\title{
Effect of Aggregate Shapes on the Properties of Concrete
}

\author{
${ }^{1 *}$ Oluwasola, E. A., ${ }^{1}$ Afolayan, A., ${ }^{2}$ Ipindola, O. O., ${ }^{3}$ Popoola, M. O and ${ }^{1}$ Oginni, A. O \\ ${ }^{1}$ Department of Civil Engineering Technology, Federal Polytechnic Ede, Osun State, Nigeria. \\ ${ }^{2}$ Department of Civil Engineering Technology, Federal Polytechnic Ile Oluji, Ondo State, Nigeria. \\ ${ }^{3}$ Department of Civil Engineering Technology, Moshood Abiola Polytechnic Abeokuta, Ogun State, Nigeria. \\ *Corresponding E-mail: akinnolu@yahoo.com or akinnolu@gmail.com
}

\begin{abstract}
Aggregates constitute more than 90\% of concrete and significantly determine the strength of concrete. In this study, the shape characteristics such as flakiness and elongation were determined using elongation and thickness gauge. The aggregate used for the study is granite. Aggregate crushing value and aggregate impact value tests were performed on the aggregate while slump test, water absorption test, compressive strength test and flexural strength test were carried out on concrete. A total of one hundred and thirty-two concrete cubes were produced using 1:2:4 and 1:3:6 mix each for the compressive strength test and forty-eight reinforced concrete beams were produced for flexural strength test. The slump for all the samples tested was examined to be true. The compressive strength of the concrete cube was greatly affected by the shape of aggregate used and it was noted that; for lower percentage of flaky and elongated aggregate the compressive strength is moderately high compared to when the percentage is high. The highest obtained compressive strength, $15 \mathrm{~N} / \mathrm{mm}^{2}$ is in compliance with the concrete compressive strength of normal 1:2:4 mix as stipulated in ASTM C109, Also, with 30\% of elongated aggregate and 30\% of flaky, the flexural strength of $7.03 \mathrm{~N} / \mathrm{mm}^{2}$ was obtained. This shows that aggregate shape is a very important property of coarse aggregate that must be put into consideration in production of quality concrete for construction works.
\end{abstract}

Keywords: Aggregate, Flaky, Concrete, Compressive and flexural Strength.

\section{Introduction}

Approximately, $80 \%$ of the total volume of concrete consists of aggregate. Aggregate characteristics significantly affect the performance of fresh and hardened concrete and have an impact on the cost of concrete. Numerous experimental studies have been conducted to examine the influence of aggregate characteristics, such as size, shape, surface texture and aggregate mineralogy, on the mechanical properties of the interface. (Anderson et al., 2016; Hudson, 1999; Neville, 2003; Rocco and Elices, 2009). The aggregates not only make concrete economical by occupying more volume, but also impart volume stability and increase durability. Also, the particle shape characteristics of the aggregate can significantly affect the workability, strength, and durability of the concrete produced (Erdogan, 2005; Erdogan et al., 2006). The shape of aggregate particles can significantly influence certain properties of concrete, both in its fresh and hardened states (Yoon et al., 2015; Jamkar and Rao, 2004).

Also, the shape of aggregates used in concrete is an important parameter that helps in determine many concrete properties, especially the rheology of fresh concrete and early-age mechanical properties (Erdogan, 2005; Erdogan et al., 2006). Aggregates shape, texture and grading have a significant effect on the performance of fresh concrete. Aggregate mixture with well-shaped, rounded, and smooth particles require less paste for a given slump than mix with flat, elongated, angular, and rough particles. At the same time, uniform grading with proper amounts of each size result in aggregate mixture with high packing and in concrete with low water demand. As a result, they are less expensive and will have less durability problems caused by the paste such as heat 
generation, porosity, and drying shrinkage (Quiroga and Fowler, 2004). Flaky, elongated, angular, and rough particles have high voids and require more sand to fill voids and to provide workable concrete, thus increasing the demand for water. Flaky and elongated particles tend to produce harsh mixtures and affect finish-ability (Erdogan et al., 2006). Additionally, research shows that there is a clear relationship between shape, texture, and grading of aggregates and the voids content of aggregates. In fact, flaky, elongated, angular, and unfavourably graded particles lead to higher voids content than, cubical, rounded, and, well graded particles (Quiroga and Fowler, 2004). Particle shape is important to the suitability of the aggregates with respect to their usage in several engineering materials. Elongated particles compared to cubic particles have a tendency to break along their long axis (Piotrowska et al., 2014; Fernlund, 2005a). Thus, particle form affects the strength of the aggregates and life expectancy of the materials such as concrete, asphalt, and railroad aggregate. Spherical particles result in good rheological character in contrast to platy particles that determine the rheological character of concrete paste. Aggregates with a rough surface compared to a smooth surface will bind more securely in both asphalt and concrete (Yazdanbakhsh et al., 2016; Fernlund, 2005b).

However, some studies are focused on the effect of aggregate shape on the hardened concrete properties. The strength and the stiffness of coarse aggregate directly influence the behaviour of hardened concrete. Although in normal concrete, mix strength is controlled by the paste or by the transition zone between paste and aggregate, the strength of high-performance concrete depends not only on the strength but also on the mineralogy of coarse aggregate. Concrete efficiency as well depend on the nomenclature of its constituents (fine and coarse aggregate). Similarly, Neville and Brooks (2010) indicated that flat particles produce lower compressive strength. By virtue of the spherical aggregate surface area is less and because of less friction of spherical aggregates in concrete, workability is better than concretes produced with other aggregate types. Irregular shape and rougher texture of angular aggregate demand more water than spherical aggregated. The slump of concretes produced of mixture aggregates is higher than the slump of concretes produced of flat and elongated aggregate (Matias et al., 2013; Neville, 2010). Comparing the strength value between angular and smooth aggregates when slump is constant, there is no significant variation, as angular aggregates require more water than smooth aggregates. The majority of researchers that have studied aggregate shapes mainly concentrated on the hardened concrete and there is a scarce number of researchers who have actually investigated the effect of aggregate shapes on the properties of fresh concrete and on flexural strength of beam.

\section{Materials and Methods}

\section{Material collection and preparation}

The granite with $19 \mathrm{~mm}$ maximum size was obtained from a quarry site located in Osun State and river sand obtained from Ede in Osun State was utilized as fine aggregate. The laboratory tests carried out on the aggregate were x-ray fluorescence test, sieve analysis, flakiness and elongation index test, while water absorption, compressive strength test and flexural strength were carried out on hardened concrete. The fresh concrete was subjected to only slump test. X-Ray fluorescence test presents the oxides that are present in the aggregates and the degree at which each oxide reacts with cementitious substance varies. The particle size distribution tests give an insight into the amount of fines particles present in the aggregate which influence the strength of concrete.

\section{Preparation of concrete}

Two batches of concrete were produced using mix ratio 1:2:4 and 1:3:6 with water- cement ratio of 0.55 for the two mixes. Concrete mixes were designed to produce M15 and M10 grade of concrete. The type of cement and fine aggregate were same for all the mixes. Before the concrete mixing 
begins, all the mix materials were weighted and prepared according to the mix design method for M15 and M10 grade of concrete. The mixing of concrete was carried out mechanically. The quantity of the cement was measured and mixed thoroughly with the fine aggregate. The coarse aggregate was varied from $0 \%$ elongated and $100 \%$ flaky to $100 \%$ elongated and $0 \%$ flaky, the measurement was done and the mixture was mixed thoroughly with the appropriate quantity of water until the mix appeared in uniform colour and consistent. The sample of both flaky and elongated aggregate is illustrated in Figure 1. The mix proportion is presented in Table 1.

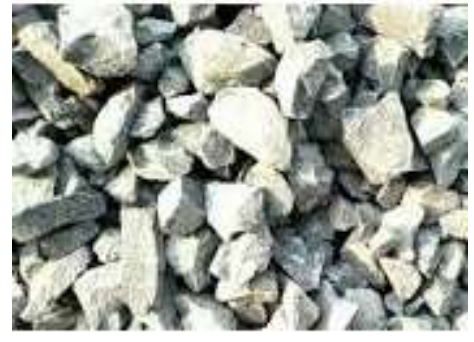

Flaky Aggregate

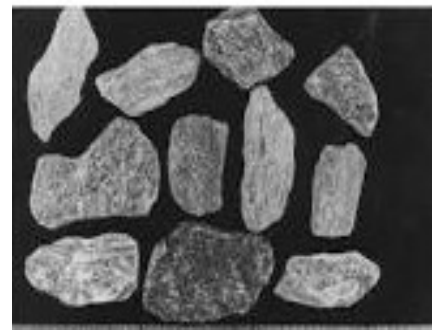

Elongated Aggregated

Figure 1: Sample of flaky and elongated aggregate

Table 1: Mix proportion

\begin{tabular}{cc}
\hline $\begin{array}{c}\% \text { of elongated aggregate } \\
(\%)\end{array}$ & $\%$ of flaky aggregate $(\%)$ \\
\hline 00 & 100 \\
10 & 90 \\
20 & 80 \\
30 & 70 \\
40 & 60 \\
50 & 50 \\
60 & 40 \\
70 & 30 \\
80 & 20 \\
90 & 10 \\
100 & 00 \\
\hline
\end{tabular}

\section{Slump test}

The workability test was performed in accordance to ASTM C1437 to measure the distance that concrete compacted in a cone will slump down after the removal of conical mould. Slump test is the most commonly used method of measuring consistency of concrete which can be employed either in laboratory or at site of work. The mould for this test is a frustum of $300 \mathrm{~mm}$ high and the top and bottom diameters are $100 \mathrm{~mm}$ and $200 \mathrm{~mm}$ respectively, it was placed on a smooth horizontal surface with smaller opening at the top. Slump cone was first oil and then filled with concrete in three layers, each layer was tamped twenty-five times with standard steel rod of $16 \mathrm{~mm}$ diameter and the top surface was smooth with hand trowel. The mould was firmly held against its base during the entire operation.

\section{Water absorption test}

The test was performed in conformity with procedures stated in BS 5669. Surface water and grit were wiped off the specimens and any projecting fines removed. Specimens when received dry was kept in water for 24 hours. The container was filled with distilled water at room temperature so that the specimens had at least $25 \mathrm{~mm}$ of water above their surface. 


\section{Casting of concrete cube}

The mixed concrete was carefully placed inside the metal mould designed for cube $150 \mathrm{~mm} \times 150 \mathrm{~mm} \times 150 \mathrm{~mm}$ and tamped for proper compaction until it levels the surface of mould. The cast cubes were labelled for easy identification

\section{Production of reinforced concrete beam $(75 \mathrm{~mm} \times 150 \mathrm{~mm} \times 350 \mathrm{~mm})$}

High yield reinforcement of $10 \mathrm{~mm}$ diameter was used for both main bars and nominal bars, two stirrups of $8 \mathrm{~mm}$ was used to hold the main and nominal reinforcement for each beam produced. The mixed concrete was poured into the mould carefully and tamped in order to ensure adequate compaction of concrete and also to avoid honey-combing of concrete at the surface of the mould. The test was performed in accordance to ASTM C1812.

\section{Compressive strength of concrete cubes}

On the second day after casting, the concrete cubes and beams were removed from the mould by losing the bolts of the moulds and were placed in the concrete curing tank as stated in ASTM C109. It was ensured the concrete cubes were completely submerged in the water. After 28 days of curing, the cubes were removed from curing tank and taken to laboratory for compressive strength test.

\section{Flexural Strength of Beam}

After 28days, the immersed beams were taken to structural laboratory at Osun State University, Osogbo for flexural strength test. The test was carried out as stated in ASTM C348. Universal testing machine of $2000 \mathrm{KN}$ was used to transfer load centrally on the beam. Electronic hydraulic control machine was used to display the load resulting from testing each sample.

\section{Results and Discussion}

\section{Aggregate properties}

The properties of aggregate were established and summarised as shown in Table 2. The shapes of the aggregate affect the properties of fresh concrete than hardened concrete. A smooth surface can improve workability while an angular surface generates a strong bond between the parts of the paste and the aggregate creating a higher strength.

Table 2. Properties of the Granite

\begin{tabular}{lcc}
\hline Property & Elongated & Flaky \\
\hline Aggregate crushing value (\%) & 19.11 & 20.76 \\
Aggregate impact value (\%) & 21.22 & 24.89 \\
Water absorption (\%) & 0.57 & 0.73 \\
\hline
\end{tabular}

\section{X-Ray florescence (XRF)}

The properties of coarse aggregate used was investigated using $\mathrm{X}$-ray florescence test, which gives the detailed chemical composition of the constituent of granite are presented in Table 3. As listed the major chemical oxide components detected in the granite aggregate are $\mathrm{SiO}_{2}, \mathrm{Al}_{2} \mathrm{O}_{3}, \mathrm{CaO}, \mathrm{K}_{2} \mathrm{O}$, $\mathrm{Fe}_{2} \mathrm{O}_{3}$ and $\mathrm{Na}_{2} \mathrm{O}$. 
Table 3. Chemical composition of the constituents of granite

\begin{tabular}{cc}
\hline Oxide content & Percentage (\%) \\
\hline $\mathrm{SiO}_{2}$ & 65.60 \\
$\mathrm{Al}_{2} \mathrm{O}_{3}$ & 15.80 \\
$\mathrm{CaO}$ & 4.90 \\
$\mathrm{~K}_{2} \mathrm{O}$ & 4.40 \\
$\mathrm{Fe}_{2} \mathrm{O}_{3}$ & 3.80 \\
$\mathrm{Na}_{2} \mathrm{O}$ & 3.48 \\
$\mathrm{MgO}$ & 1.74 \\
$\mathrm{MnO}$ & 0.28 \\
\hline
\end{tabular}

\section{Sieve analysis}

The particle size distribution curve is shown in Figure 2. The sieve analysis shows the percentage of aggregate size present in the total sample of coarse aggregate. The aggregate size passing the sieve $19 \mathrm{~mm}$ and retained on sieve size $9.5 \mathrm{~mm}$ has the highest percentage $(41.231 \%)$ of the total coarse aggregate. This in turns increase the workability of the concrete. Particle shape significantly affects the water cement ratio by its effect on water demand and amount of paste needed for workability of a given mixture. The uniformity coefficient and coefficient of curvature were found to be 2.783 and 1.105 respectively. This indicates that the aggregate is well graded since its coefficient of curvature lies between 1 and 3 . In addition, it can be deduced that there is no excess of particles in any size range.

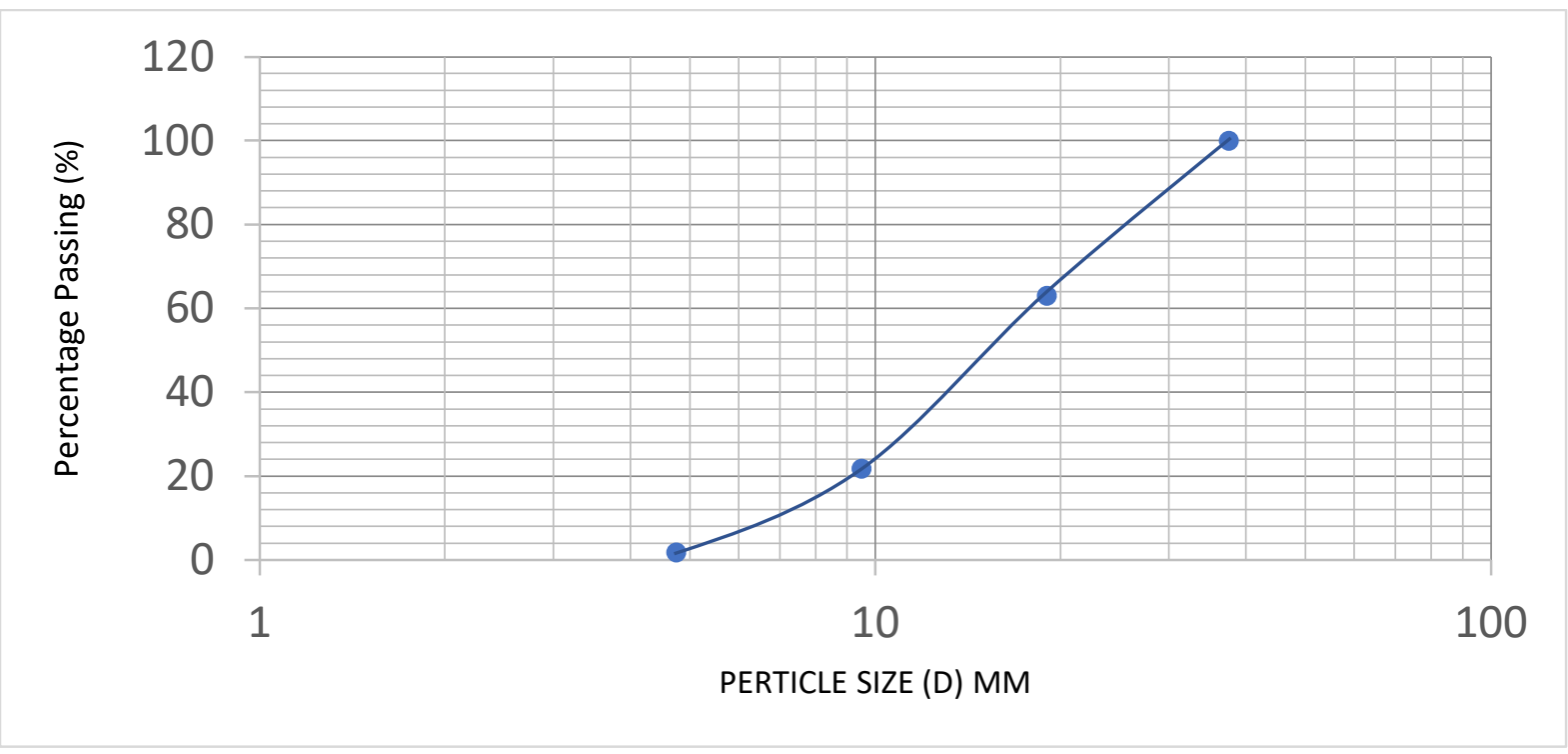

Figure 2: Particle size distribution of the Aggregate

\section{Slump}

The comparison of the slump result for the two mix ratios varying the percentage of aggregate used is shown in Figure 3. The slump for all the samples tested was examined to be true, but due to the water-cement ratio and the amount of aggregate used for each mix ratio, the result shows that the shape of the aggregate used has little or no effect on the slump for mix 1:3:6, because the highest difference between each slump value is $2 \mathrm{~mm}$. The concrete mix has the highest slump of $3 \mathrm{~mm}$ which is not so different from the lowest slump of $1 \mathrm{~mm}$. This does not happen because of aggregate shape only; it is also affected by water-cement ratio. Also, for mix ratio 1:2:4 the slump for all the mixes are very close to one another but the highest slump $(6 \mathrm{~mm})$ when compared to the other mix is a bit 
higher than the lowest slump $(2 \mathrm{~mm})$. This implies that concrete made with the use of mix ratio 1:2:4 with 0.55 water-cement ratio is more workable compared to that of mix 1:3:6 which agrees with the findings of Gambhir (2004) and Panarese et al., (2002).

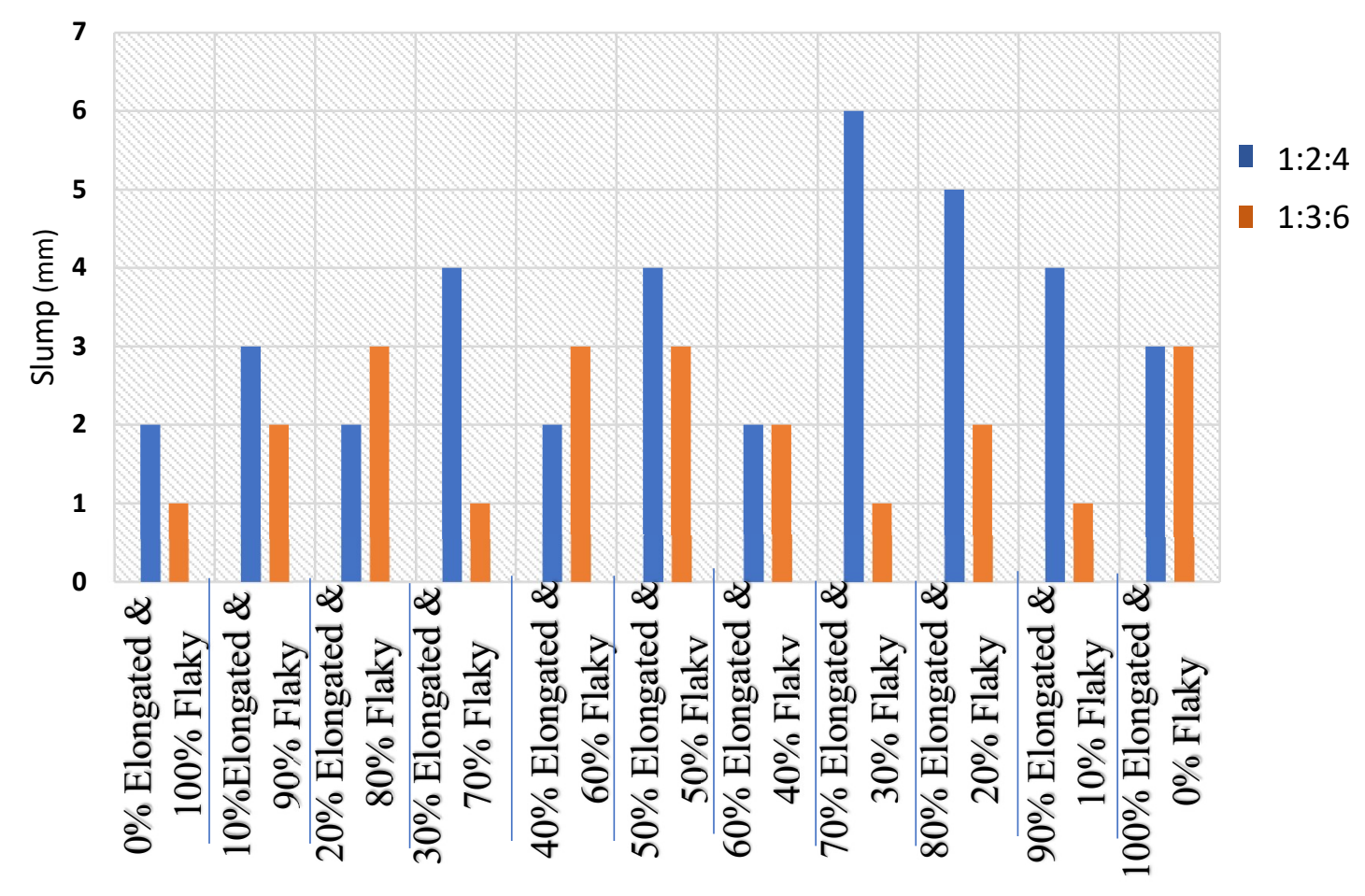

Figure 3: Comparison of slump test for concrete of mix 1:2:4 and 1:3:6

\section{Water absorption}

This test was carried out for only beams and it presents the ability of the hardened concrete to absorb water, and the results presented in Table 4 indicates that the beams with $40 \%$ elongated and $60 \%$ flaky aggregate, 50\% elongated and 50\% flaky aggregate and 0\% elongated and 100\% flaky aggregate possess low absorbability of 1.35, 1.4 and 2.3 respectively. Considering the result and proper examination, it can be stated that flaky aggregates absorb more water compared to elongated aggregate which in turn renders the concrete less durable compare to the others with lower ability to absorb water which complies with Brink and Timms (1966).

Taking to consideration the effect of the water absorption on the flexural strength of the beams, it can be affirmed that the water absorption of hardened concrete considerably affects the flexural strength of beams with $40 \%$ elongated and 60\% flaky aggregate, 50\% elongated and 50\% flaky aggregate and $0 \%$ elongated and 100\% flaky aggregate. Reasonably low water absorption ability causes increase in the flexural strength. Effect of water absorption is the loss of concrete workability as stated by Punkki and Gjøry (1995). Another effect according to Hammer et al., (1992) is the reduction of effective water cement ratio as water penetrates into the aggregate during setting. The rate of absorption is important to foresee the loss of workability of the fresh concrete, which goes in line with the findings of Weigler et al., (1972).

\section{Compressive strength of concrete}

This test results is presented in Figure 4, the values was compared and it was observed that the cube with the greatest compressive strength is produced with $30 \%$ elongated aggregate which is cured for 28 days. It is also noted that when the concrete is $0 \%$ elongated cured for 14 days there is also increased compressive strength for mix 1:2:4 also for mix 1:3:6. With 20\% flaky aggregate for mix 
ratio 1:3:6, the compressive strength yielded the highest value $\left(15.0 \mathrm{~N} / \mathrm{mm}^{2}\right)$ as shown in Figure 3 which agrees with standard compressive strength of concrete made for mix 1:2:4 and 1:3:6 $\left(15 \mathrm{~N} / \mathrm{mm}^{2}\right.$ and $\left.10 \mathrm{~N} / \mathrm{mm}^{2}\right)$ respectively and Neville and Brooks (2010), which says flat or flaky aggregate produce lower compressive strength which implies that blade (flat and elongated) and disk (flat) aggregates has low strength. The amount of flaky and elongated aggregate present in each mix has effect of either increasing or reducing the compressive strength of concrete cube (Anderson et al., 2016). Aggregate with angular surface produces a strong bond between the parts of the paste and creating a higher strength while aggregate with smooth surface can improve workability of the concrete.

Table 4: Water absorption of concrete beams

\begin{tabular}{cc}
\hline$\%$ of elongated /flaky aggregate $(\%)$ & Absorption $(\%)$ \\
\hline $0 / 100$ & 2.30 \\
$10 / 90$ & 2.65 \\
$20 / 80$ & 2.85 \\
$30 / 70$ & 3.10 \\
$40 / 60$ & 1.35 \\
$50 / 50$ & 1.40 \\
$60 / 40$ & 3.50 \\
$70 / 30$ & 2.30 \\
$80 / 20$ & 2.10 \\
$90 / 10$ & 2.20 \\
$100 / 0$ & 1.70 \\
\hline
\end{tabular}

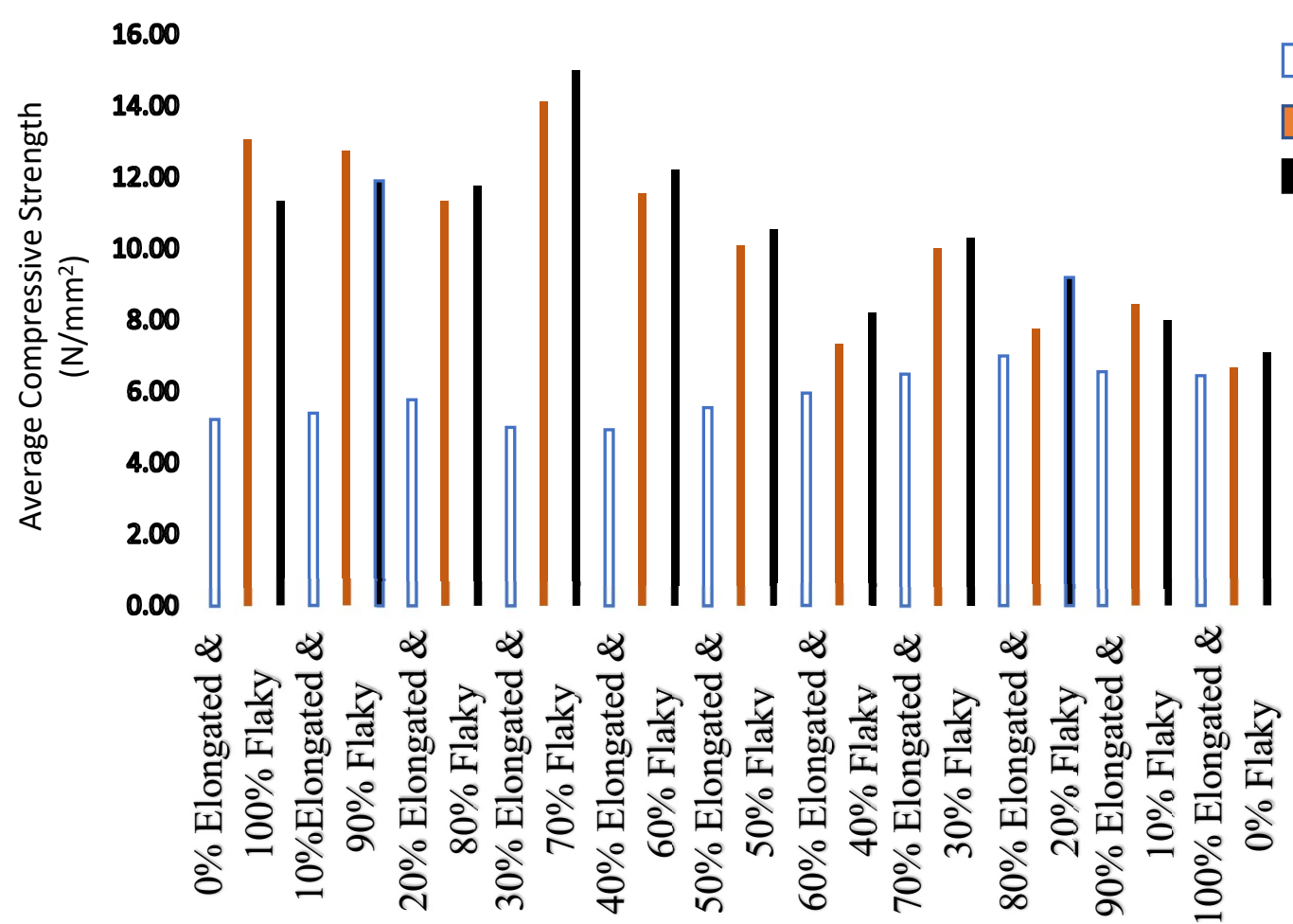

Figure 4a: Compressive strength of concrete cubes with mix 1:2:4 


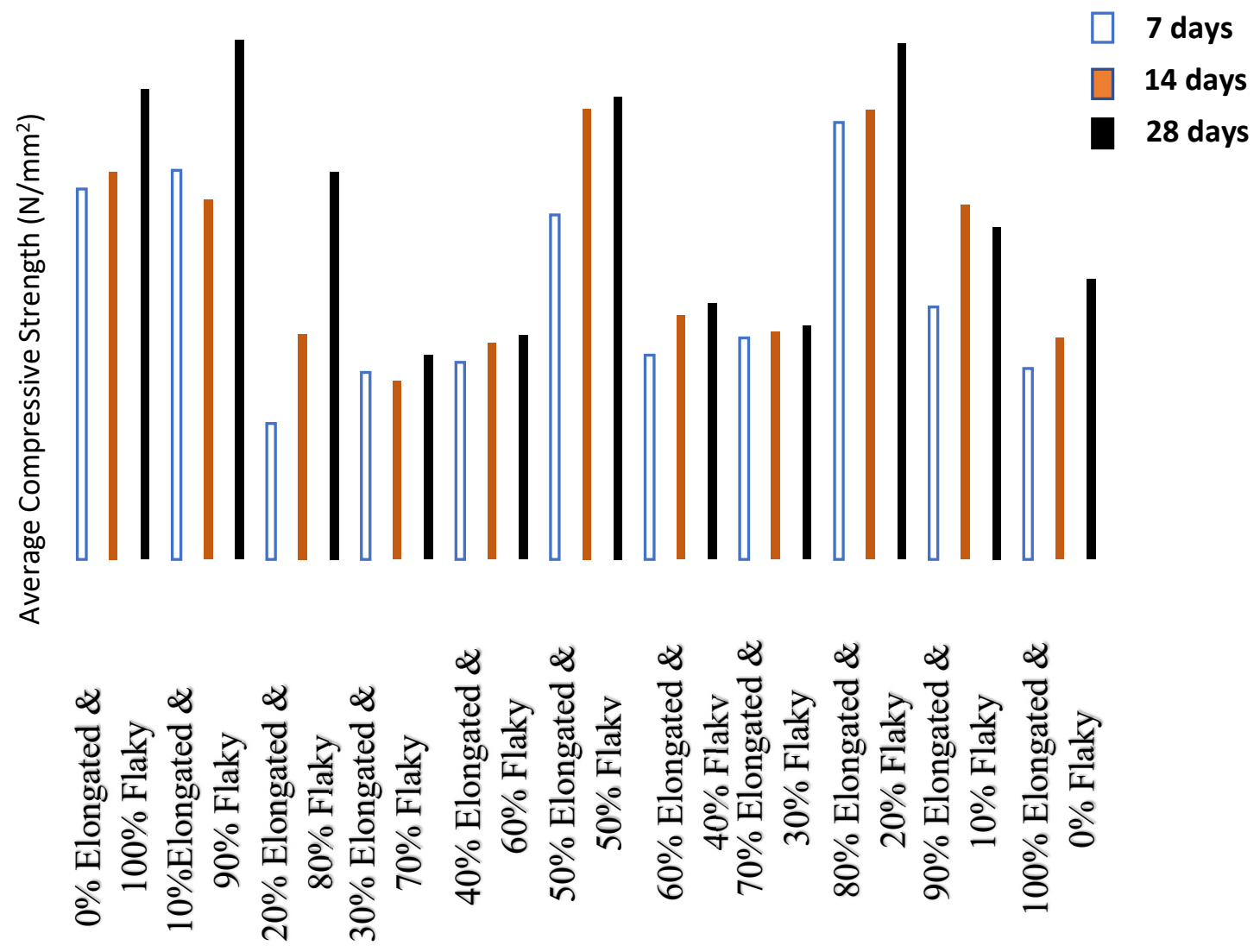

Figure 4b: Compressive strength of concrete cubes with mix 1:3:6

\section{Flexural strength of reinforced concrete beam}

The flexural strength of the concrete beams is presented in Figure 5. The result indicates that at $30 \%$ of elongated aggregate, the strength reached the maximum also at 30\% flaky the strength yields moderately high strength for the total beams tested. The result of this test is greater than the normal flexural strength as stated by American Society for Testing (ASTM) C31 which is $5.5 \mathrm{~N} / \mathrm{mm}^{2}$. One factor that contributed to the increase in the flexural strength value is the addition of reinforcement to the normal mass concrete (Yazdanbakhsh et al., 2016) which gives the greater flexural strength of $7.03 \mathrm{~N} / \mathrm{mm}^{2}$. Also, the bond with cement paste may be weaken due to accumulation of bleed water under the relatively large surface area of the particles of aggregate. Concrete with elongated aggregate ordinarily has a higher flexural strength than concrete with flaky aggregate. 


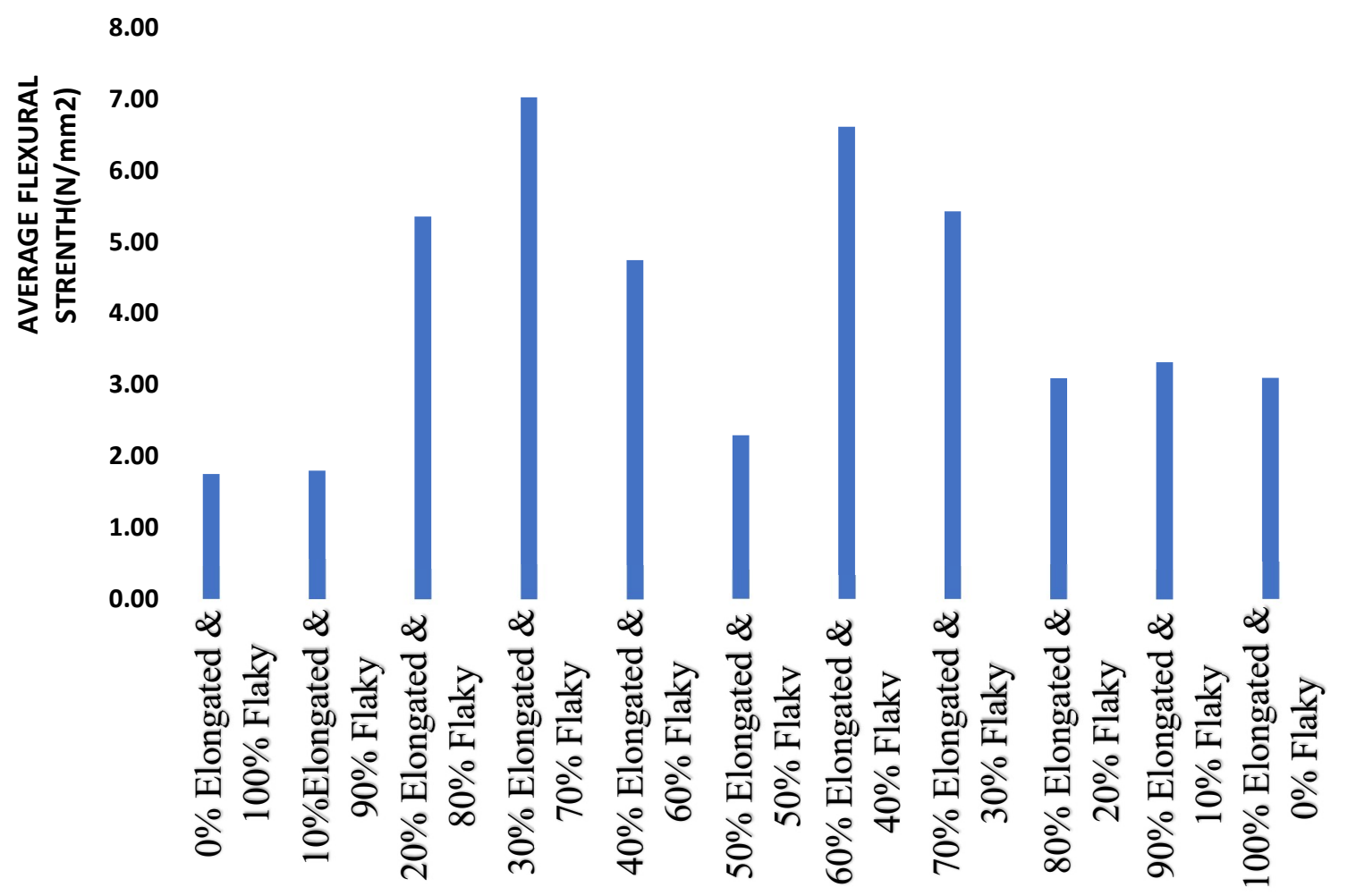

Figure 5: Flexural strength of concrete beam with mix 1:2:4

\section{Conclusion}

The following conclusions were made based on the test results obtained from the laboratory. The slump test results indicated increased percentage of flaky and elongated aggregates reduces workability. Considering the result of water absorption, flaky aggregates absorb more water compared to elongated aggregate. The compressive strength of the concrete cube was greatly affected by the shape of aggregate used and it was noted that; for lower percentage of flaky and elongated aggregate the compressive strength is moderately high compared to when the percentage is high. The highest compressive strength, $15 \mathrm{~N} / \mathrm{mm}^{2}$ is in compliance with the concrete compressive strength of normal 1:2:4 mix. With $30 \%$ of elongated aggregate and $30 \%$ of flaky, it was noted that the flexural strength was high compared to presence of higher percentage of flaky and elongated aggregate which yields lower flexural strength.

\section{References}

Anderson, D. J., Smith, S. T., and Au, F. T. (2016) Mechanical Properties of Concrete Utilising Waste Ceramic as Coarse Aggregate. Construction and Building Materials, 117: 20-28.

Brink, R. H. and Timms, A. G. (1966) Weight, Density, Absorption, and Surface Moisture, Significance of Tests and Properties of Concrete and Concrete-Making Materials, ASTM STP169A, ASTM International, West Conshohocken PA, p. 432.

Erdogan, S. T. (2005) Determination of Aggregate Shape Properties Using X-Ray Tomographic Methods and The Effect of Shape on Concrete Rheology, Ph.D. Dissertation, University of Texas at Austin.

Erdogan, S. T., Quiroga, P. N., Fowler, D. W., Saleh, H. A., Livingston, R. A., Garboczi, E. J., Ketcham, P. M., Hagedorn, J. G. and Satterfield, S. G. (2006) Three-Dimensional Shape 
Analysis of Coarse Aggregates: New Techniques for and Preliminary Results on Several Coarse Aggregates and Reference Rocks, Cement and Concrete Research, 36: 1619-1627.

Fernlund, J. M. R. (2005a), Image Analysis Method for Determining 3-D Shape of Coarse Aggregate, Cement and Concrete Research, 35:1629-1637.

Fernlund, J. M. R. (2005b), 3-D Image Analysis Size and Shape Method Applied To the Evaluation of the Los Angles Test, Engineering Geology, 77: 57-67.

Gambhir, M. L. (2004). Concrete Technology. Tata McGraw-Hill. Pp. 127, 128.

Hudson, B. (1999), Modification to the Fine Aggregate Angularity Test, Proceedings, Seventh Annual International Center for Aggregates Research Symposium

Jamkar, S. S. and Rao C. B. K (2004), Index of Aggregate Particle Shape and Texture of Coarse Aggregate as a Parameter for Concrete Mix Proportioning, Cement and Concrete Research, 34:2021-2027.

Matias, D., De Brito, J., Rosa, A., and Pedro, D. (2013). Mechanical Properties of Concrete Produced with Recycled Coarse Aggregates-Influence of The Use of Superplasticizers. Construction and Building Materials, 44:101-109.

Neville, A. M. (2003) Properties of Concrete, Longman Scientific and Technical, England.

Neville, A. M. and Brooks, J. J. (2010) Concrete Technology, Second Edition, Longman Scientific and Technical, England.

Panarese, W. C., Kosmatka, S. H. and Kerkhoff, B. (2002). Design and control of concrete mixtures Skokie III. Portland Cement Association.

Piotrowska, E., Malecot, Y., and Ke, Y. (2014) Experimental Investigation of the Effect of Coarse Aggregate Shape and Composition on Concrete Triaxial Behaviour. Mechanics of Materials, 79: 45-57.

Punkki, J., and Gjørv, O. E. (1995) Effect of Water Absorption by Aggregate on Properties of High Strength Lightweight Aggregate Concrete, CEB/FIP - 185 - International Symposium on Structural Lightweight Aggregate Concrete, Holand et al., (ed.), Sandefjord, Norway, pp.604616.

Quiroga, P. N. and Fowler, D. W. (2004) The Effects of Aggregates Characteristics on the Performance of Portland Cement Concrete, International Center for Aggregate research (ICAR) Report No. 104-1F

Rocco, C. G. and Elices, M. (2009) Imaging Indices for Quantification of Shape, Angularity, and Surface Texture of Aggregates. Engineering Fracture Mechanics, 76: 286-298

Weigler, H., Karl, S. and Lieser, P. (1972). The Bending Load Capacity of Reinforced Lightweight Concrete, Betonwerk and Fertigteil-Technik. 38(5): 324-334

Yazdanbakhsh, A., Bank, L. C., and Chen, C. (2016) Use of Recycled FRP Reinforcing Bar in Concrete as Coarse Aggregate and Its Impact on the Mechanical Properties of Concrete. Construction and Building Materials, 121: 278-284.

Yoon, M., Kim, G., Choe, G. C., Lee, Y., and Lee, T. (2015) Effect of Coarse Aggregate Type and Loading Level on the High Temperature Properties of Concrete. Construction and Building Materials, 78:26-33. 